\title{
Dissociation Constants of Some Quinoline Derivatives in Mixed Solvent mixture
}

\author{
Shipra Baluja* \\ Department of Chemistry, Saurashtra University, Rajkot_360005, Gujarat, India \\ *E-mail address: shipra_baluja@rediffmail.com
}

\begin{abstract}
The dissociation constants of some derivatives of quinoline have been determined by Calvin Bjerrum $\mathrm{pH}$ titration method in DMF-water $(60: 40 \mathrm{v} / \mathrm{v})$ mixture at $308.15 \mathrm{~K}$. It is observed that dissociation constant depends on the substituents present in the compound.
\end{abstract}

Keywords: Dissociation constant; quinoline derivatives; $\mathrm{pH}$; DMF-water mixture

\section{INTRODUCTION}

The dissociation constant provides useful information about structure, toutomeric equilibria, solvent- solute interactions etc. [1-3]. In continuation with our previous work, in the present paper dissociation constants of some derivatives of quinoline have been studied. Literature survey shows that various quinoline derivatives are known to have broad spectrum of biological activities [4-6], such as antifungal [7], antibacterial [8], antioxidant [9], antiparasitic [9], antimicrobial [10], anti tubercular [11], anticytoxic [12], antiinflammatory $[13,14]$, antiviral [15], antiparasitic [15] etc. Some other pharmacological activities of these derivatives have also been reported by some workers [16-18].

Some new quinoline derivatives are synthesized and their dissociation constants have been determined in DMF-water mixtures by Calvin Bjerrum $\mathrm{pH}$ titration method at $308.15 \mathrm{~K}$.

\section{EXPERIMENTAL}

Five new Quinoline derivatives are synthesized in the laboratory and the reaction scheme is:

\section{REACTION SCHEME}<smiles>O=Cc1cc2cc(F)ccc2nc1Cl</smiles><smiles>[R][C@H](C)[C@H](C)N</smiles><smiles>[R]=NCc1cc2cc(F)ccc2nc1Cl</smiles>

$\mathrm{R}-\mathrm{NH}_{2}$ 
The synthesized compounds were recrystallized and their purity was checked by thin layer chromatography. Further, the characterization was done by IR, NMR and mass spectral analysis. The physical constants of these derivatives are given in Table 1.

Dissociation constant: The chemical used were of AR grade. Solutions of nitric acid $(1.0 \mathrm{M})$, sodium hydroxide $(0.5 \mathrm{M})$ and sodium nitrate $(1.0 \mathrm{M})$ were prepared using Mill-Q water (Millipore Pvt. Ltd. Bangalore, India). The solutions of synthesized compounds $(0.1 \mathrm{M})$ were prepared in DMF. An electrical balance (Mettler Toledo AB204-S) with an accuracy of $\pm 0.1 \mathrm{mg}$ was used for solution preparation.

The Calvin Bjerrum $\mathrm{pH}$ titration method [19] was used to determine dissociation constants of synthesized compounds. For this, a Systronic pH meter (Model No. EQ 664) was used. The glass and saturated calomel electrodes were used as indicator and reference electrodes respectively. Before measurement, the $\mathrm{pH}$ meter was calibrated with buffer solution of known $\mathrm{pH}$. The following sets of mixtures were prepared for titration:

(I) Blank Solution: It consists of $2 \mathrm{ml} \mathrm{HNO}_{3}(0.1 \mathrm{M})+4 \mathrm{ml}$ water $+30 \mathrm{ml} \mathrm{DMF}+4.0$ $\mathrm{ml} \mathrm{NaNO}(1.0 \mathrm{M})$.

(II) Test solution: It consists of $2 \mathrm{ml} \mathrm{HNO} 3(0.1 \mathrm{M})+4 \mathrm{ml}$ water $+28 \mathrm{ml} \mathrm{DMF}+2.0 \mathrm{ml}$ compound solution $(0.1 \mathrm{M})+4.0 \mathrm{ml} \mathrm{NaNO} 3(1.0 \mathrm{M})$. $(\mathrm{v} / \mathrm{v})$.

Thus, total volumes $\left(V^{\circ}\right)$ in each set is equal $40.0 \mathrm{ml}$ and DMF : water ratio $60: 40$

The above mentioned solutions were allowed to attain a constant temperature ( 308.15 $\mathrm{K})$ and then titrated against standard sodium hydroxide solution $(0.5 \mathrm{M})$ under an inert atmosphere of nitrogen. The change in the $\mathrm{pH}$ of solution with each addition of alkali was recorded.

\section{RESULTS AND DISCUSSION}

The $\mathrm{pH}$ values are plotted against volume of alkali added for both the solutions and from the two titration curves, the average number of protons associated with ligand $\left(\mathrm{n}_{\mathrm{H}}\right)$ can be calculated by Irring and Rossotti equation:

$$
n_{H}=Y-\frac{\left(V^{/ /}-V^{/}\right)\left(N^{0}-E^{0}\right)}{\left(V^{0}+V^{/}\right) T_{L}^{0}}
$$

where $Y$ is the number of displaceable protons per compound molecule. For the studied compounds, value of $Y$ is one.

$V^{\prime}$ and $V^{\prime /}$ are the volume of alkali required at the same $\mathrm{pH}$ for both blank and compound titration curves respectively; $V^{\circ}$ is the initial volume of the test solution. $\mathrm{N}^{0}, \mathrm{E}^{0}$ and $\mathrm{T}_{\mathrm{L}}^{0}$ are the initial concentration of the alkali, acid and compound respectively.

The values of $n_{H}$ are found to be between 0 to 1 for all the compounds suggesting thereby the presence of one dissociable proton.

The dissociation constants of compounds were determined by two methods: average method and half-integral method. In average method, for each compound, the values of dissociation constants were evaluated at different $\mathrm{pH}$ using following equation: 


$$
\log p K=p H+\log \left[\frac{n_{H}}{\left(n_{H}-1\right)}\right]
$$
Table 1.

From these $\log \mathrm{pK}$ values, the average value of $\mathrm{pK}$ was calculated and is reported in

In half-integral method, $\mathrm{n}_{\mathrm{H}}$ values are plotted against $\mathrm{pH}$ and the $\log \mathrm{pK}$ values at $\mathrm{n}_{\mathrm{H}}$ $=0.5$ were evaluated for each compound and are given in Table 1 .

It is observed from Table 1 that there is good agreement between the values evaluated by two methods.

Out of five compounds, SB-5 and SB-3 are more basic whereas SB-2 is least basic means more acidic. In all the compounds, central moiety is same but different substitutions are present as shown in Table 1. SB-5 contains 3-chloro and 4-fluoro groups whereas SB-3 contains 4-chloro group only. Thus, the more basic character of SB-5 and SB-3 may be due of positive resonating effect of halogen groups which donate lone pair of electrons to phenyl ring.

Table 1. Physical constants of Schiff bases.

\begin{tabular}{|c|c|c|c|}
\hline S. No. & Compound Code & \multicolumn{2}{|c|}{$\mathrm{pK}$} \\
\hline & & Average method & Half-integral method \\
\hline 1 & SB-1 & 11.09 & 11.10 \\
\hline 2 & SB-2 & 10.93 & 10.95 \\
\hline 3 & SB-3 & 11.37 & 11.40 \\
\hline 4 & SB-4 & 11.07 & 11.08 \\
\hline 8 & SB-5 & 11.40 & 11.38 \\
\hline
\end{tabular}

*Acetone: Benzene: 2:8

Table 2. Dissociation constants (pK) of synthesized quinoline derivatives by Average and half-integral methods.

\begin{tabular}{|c|c|c|c|c|c|c|c|}
\hline $\begin{array}{c}\text { S. } \\
\text { No. }\end{array}$ & $\begin{array}{c}\text { Comp. } \\
\text { code }\end{array}$ & R & Molecular formula & $\begin{array}{c}\text { M. W } \\
(\mathrm{g} / \mathrm{mol})\end{array}$ & $\begin{array}{c}\text { Rf } \\
\text { value }\end{array}$ & $\begin{array}{c}\text { M.P } \\
\text { 0C }\end{array}$ & $\begin{array}{c}\text { Yield } \\
\%\end{array}$ \\
\hline 1. & SB-1 & 4-OCH3-C6H4- & C17H12ClFN2O & 314 & 0.53 & 192 & 62 \\
\hline 2. & SB-2 & 4-CH3-C6H4- & C17H12ClFN2 & 298 & 0.52 & 168 & 65 \\
\hline 3. & SB-3 & 4-Cl- C6H4- & C16H9Cl2FN2 & 319 & 0.47 & 217 & 55 \\
\hline 4. & SB-4 & 2-OCH3-C6H4- & C17H12ClFN2 & 298 & 0.34 & 205 & 59 \\
\hline 8. & SB-5 & 3-Cl-4-F-C6H3- & C16H8Cl2F2N2 & 337 & 0.44 & 211 & 69 \\
\hline
\end{tabular}

The more acidic character of SB-2 is because of negative inductive effect of $4-\mathrm{CH}_{3}$ group. Thus, the presence of different substituent influences the dissociation of compound due to their different effects [20]. Similar results have been reported by earlier studies on pyrimidine compounds where polarity of substituent affects basicity of compounds [21]. SB-2 is followed by SB-1 and SB-4. Both SB-1 and SB-4 contain methoxy groups at para and ortho positions respectively.

Thus, it is concluded that ionization of compound depends on inductive effects of substituent present in the compound. 


\section{References}

[1] McDanial, D. H.; Brown, H. C.; Haffinger, O.; Brande, E. A.; Nachod, F. Academic Press, Inc, N. W. 1955.

[2] Seleem, H. S.; El-Shetary, B. A.; Khalil, S. M. E.; Shebl, M. J. Serb. Chem. Soc., 2003, $68,729$.

[3] Taha, M.; Fazary, A. J. Chem. Thermo., 2005, 37, 43.

[4] Kumar, S; Bawa, S.; Gupta, H., Mini Rev. Med. Chem., 2009, 9, 1648.

[5] Musiol, R.; Jampilek, J.; Kralova, K.; Richardson, D. R.; Kalinowski, D.; Podeszwa, B.; Finster, J.; Niedbala, H.; Palka, A; Polanski, J., Bioorg. Med. Chem.,2007, 15, 1280.

[6] Marella, A.; Tanwar, O. P.; Saha, R.; Ali, M. R.; Srivastava, S.; Akhter, M.; Shaquiquzzaman, M.; Alam, M. M., Saudi Pharma. J., 2013, 21, 1.

[7] Musiol, R.; Jampilek, J.; Buchta, V.; Silva, L.; Niedbala, H.; Podeszwa, B.; Palka, A; Maniecka, K. M.; Oleksyn, B.; Polanski, J., Bioorg. Med. Chem., 2006, 14, 3592.

[8] Shivaraj, Y.; Naveen, M. H.; Vijayakumar, G. R.; Aruna, D. B., J. Korean Chem. Soc., 2013, 57, 241.

[9] Manjunatha, J.R.; Bettadaiah, B.K.; Negi, P.S.; Srinivas, P., Food Chem., 2013, 136, 658.

[10] Eswaran, S.; Adhikari, A. V.; Shetty, N. S., Eur. J. Med. Chem., 2009, 44, 4637.

[11] De Souza, M. V.N.; Pais, K. C.; Kaiser, C. R.; Peralta, M. A.; Ferreira, P. M. L.; Lourenço, M. C. S., Bioorg. Med. Chem., 2009, 17, 1474.

[12] Jahromia, B. T.; Kharata, A. N.; Foroutannejad, S., Res. J. Pharma. Bio. Chem. Sci., $2011,2,61$.

[13] El-Sayed, O. A.; Al-Turki, T.M.; Al-Daffiri, H. M.; Al-Bassam, B. A.; Hussein, M. E., Boll. Chim. Farm., 2004, 143, 227.

[14] Alam, M. M.; Sarkar, D. P.; Husain, A.; Marella, A.; Shaquiquzzaman, M.; Akhter, M.; Shaharyar, M.; Alam, O.; Azam, F., J. Serb. Chem. Soc., 2011, 76, 1617.

[15] Sopková-de Oliveira Santos, J.; Verhaeghe, P.; Lohier, J.F.; Rathelot, P.; Vanelle, P.; Rault, S., Acta Crystallogr C. 2007, 63, o643.

[16] Bénard, C.; Zouhiri, F.; Bayle, M. N.; Danet, M.; Desmaële, D.; Leh, H.; Mouscadet, J. F.; Mbemba, G.; Thomas, C. M.; Bonnenfant, S.; Bret, M.; Angelo, Bioorg. Med. Chem. Lett., 2004,14, 2473.

[17] Kalluraya, B., Sreenivasa, S., Il Farmaco, 1998, 53, 399.

[18] Gonec , T.; Bobal , P.; Sujan, J.; Pesko , M.; J Guo, J.; Kralova , K.; Pavlacka , L.; Vesely , L.; Kreckova , E.; Kos , J.; Coffey, A.; Kollar, P.; Imramovsky, A.; Placek, L.; Jampilek, J., Molecules 2012, 17, 613. 
[19] Irving H.; Rossotti, H. S., J. Chem. Soc., 1954, 23,2904.

[20] Issa, Y.M.; Sherif, O.E.; Abbas, S.M.; Monatsh. Chem. 1998, 129, 985.

[21] M. Mazik, W. Zielinski, Monatsh. Chem., 1996, 127, 587.

( Received 28 January 2015; accepted 09 February 2015 ) 